Volume 2

Issue 3 - Vascular Disease

Article 2

8-14-2015

\title{
A Tale of Two Techniques: Demystifying the Myth
}

M. Fuad Jan

Follow this and additional works at: https://aah.org/jpcrr

Part of the Cardiology Commons, and the Surgery Commons

\section{Recommended Citation}

Jan M. A Tale of Two Techniques: Demystifying the Myth. J Patient Cent Res Rev 2015;2:87-94.

http://dx.doi.org/10.17294/2330-0698.1134

Published quarterly by Midwest-based health system Advocate Aurora Health and indexed in PubMed Central, the Journal of Patient-Centered Research and Reviews (JPCRR) is an open access, peer-reviewed medical journal focused on disseminating scholarly works devoted to improving patient-centered care practices, health outcomes, and the patient experience. 


\title{
A Tale of Two Techniques: Demystifying the Myth
}

\author{
M. Fuad Jan, MBBS, MD | Editorial
}

Aurora Cardiovascular Services, Aurora Health Care, Milwaukee, WI

It was the best of times, it was the worst of times, it was the age of wisdom, it was the age of foolishness, it was the epoch of belief, it was the epoch of incredulity, it was the season of Light, it was the season of Darkness, it was the spring of hope, it was the winter of despair, we had everything before us, we had nothing before us, we were all going direct to Heaven, we were all going direct the other way. ...

$$
\text { -A Tale of Two Cities, by Charles Dickens }
$$

Forty-eight years since the introduction of coronary artery bypass surgery (CABG) in $1967^{1}$ and 38 years after the first reported percutaneous coronary intervention (PCI) in a human in $1977,{ }^{2}$ the battle for supremacy between cardiac surgery and interventional cardiology as the preferred treatment modality for complex coronary artery disease (CAD) specifically, three-vessel or multivessel disease (3VD) with or without unprotected left main coronary artery disease (ULMCA) - shows no signs of receding. ${ }^{3-6}$ Interventional cardiologists have made rapid additions to their armamentarium for treating complex CAD through the development of newer-generation drugeluting stents (DES) and novel antithrombotic drugs. At the same time, cardiac surgeons have improved revascularization procedures through the implementation of bilateral left internal mammary artery grafts as well as off-pump and minimally invasive surgery.

\section{Before SYNTAX}

Historically, numerous randomized and multicenter studies (e.g. ERACI, EAST, GABI, CABRI, MASS, BARI, SIMA, LAUSANNE, RITA and TOULOUSE) ${ }^{7}$ demonstrated the superiority of CABG over PCI

Correspondence: M. Fuad Jan, MBBS, MD, 2801 W. Kinnickinnic River Parkway, Suite 840, Milwaukee, WI, 53215, T: 414-649-3909, F: 414-649-3551, Email:

publishing18@aurora.org (mainly percutaneous transluminal coronary angioplasty at that time), which led to the abandonment of balloon angioplasty and the emergence of new stents. In this more recent era (up to 2009), the results of percutaneous transluminal coronary angioplasty and stenting with bare-metal stents were compared in multiple studies (e.g. AWESOME, ARTS, SOS, ERACI, MASS, among others). Although the results in the first year were similar for patients treated with either surgery or stent, at 5 years, the reoperations in the stent group were higher due to multiple restenoses, reaffirming that $\mathrm{CABG}$ was the better option for patients with $3 \mathrm{VD} / \mathrm{ULMCA}$ disease. Almost all of these studies were criticized, as they included a very small number of randomized patients $(\sim 5 \%)$ and few patients with ULMCA, ${ }^{7}$ inconsistent with real-world experience.

\section{After SYNTAX}

In 2009, the 1-year results of the SYNTAX trial ${ }^{8,9}$ prepared the contemporary framework in which patients with $3 \mathrm{VD} / \mathrm{ULMCA}$ are now evaluated. This randomized, prospective, multicenter trial ( 85 centers in 18 countries) incorporated an "all-comers" design and consisted of patients with ULMCA disease (isolated or associated with one to three vessels) or de novo 3VD. Patients were randomized on a 1:1 basis to either CABG or PCI with a paclitaxel-eluting stent (TAXUS Express, Boston Scientific Corp., Natick, MA) or placed in nested registries when considered unsuitable for randomization by the Heart Team (i.e. a CABG nested registry for PCI-ineligible patients and a $\mathrm{PCI}$ nested registry for $\mathrm{CABG}$-ineligible patients). $\mathrm{CABG}$ techniques between the randomized and nested registry were broadly similar, except that double left and right internal mammary artery grafts were more frequently performed in the randomized $\mathrm{CABG}$ population (27.6\%) than in the CABG nested registry (16.1\%). Of the 589 stents implanted within the PCI nested registry, 57\% were the TAXUS Express, 19\% were another paclitaxel-eluting stent and 24\% were bare-metal. Four PCI-nested patients did not receive a stent. 
The "final episode" of this landmark trial was released in 2013. ${ }^{10}$ The primary endpoint was noninferiority of PCI with paclitaxel-eluting stent versus CABG for the incidence of major adverse cardiovascular and cerebrovascular events (MACCE) at 12 months. At 5-year follow-up, CABG was associated with lower rates of MACCE $(37.5 \%$ vs. $24.2 \%, \mathrm{P}<0.01)$, death $(14.6 \%$ vs. $9.2 \%, \mathrm{P}<0.01)$, myocardial infarction $(10.6 \%$ vs. $3.3 \%, \mathrm{P}<0.01)$ and repeat revascularization $(25.4 \%$ vs. $12.6 \%, \mathrm{P}<0.01)$ compared with PCI. No difference in the rate of stroke was observed between the groups $(3.0 \%$ vs. $3.4 \%, \mathrm{P}=0.66)$. The final 5 -year follow-up in patients with ULMCA disease also was published. ${ }^{11}$ In contrast to patients with $3 \mathrm{VD}$, no significant differences in MACCE were observed between PCI and CABG in patients with ULMCA disease (36.9\% PCI vs. 31\% CABG, $\mathrm{P}=0.12$ ). However, $\mathrm{CABG}$ was associated with an increased rate of stroke ( $5 \%$ vs. $14 \%, \mathrm{P}=0.03$ ), which was counterbalanced by a higher revascularization rate in the PCI group $(26.7 \%$ vs. $15.5 \%, \mathrm{P}<0.01)$. After stratification for SYNTAX score tertiles, an increase in survival was observed in PCI-treated patients with a score $\leq 32$. Conversely, CABG was associated with a reduced incidence of MACCE in patients with a score $>32$.

The anatomical SYNTAX score, with low $(<23)$, intermediate (23-32) or high $(>32)$ categories, ${ }^{8,12}$ became a sentinel tool in the SYNTAX trial and pioneered the now-popular "Heart Team" approach, in which a cardiac surgeon and interventional cardiologist determine the optimal revascularization modality for patients with $3 \mathrm{VD} / \mathrm{ULMCA}$ disease. It combines the importance of diseased vessel segment weighting (Leaman score), adverse lesion characteristics (American College of Cardiology/American Heart Association lesion classification, and total occlusion characteristics from the European TOTAL Surveillance Study) and the Medina classification system for bifurcation lesions. ${ }^{13-16}$ However, the SYNTAX score is open to criticism since it relies solely on scoring coronary anatomy and does not take potentially important prognostic information into consideration in the absence of clinical factors. ${ }^{17,18}$ Consequently, several risk stratification tools have attempted to merge the SYNTAX score with clinically based risk scores to improve the risk stratification of patients with $3 \mathrm{VD} / \mathrm{ULMCA}$ disease undergoing $\mathrm{CABG}$ or PCI compared with the SYNTAX score alone. Examples include the Clinical SYNTAX score (a combination of the SYNTAX score and the modified ACEF score [i.e. age/ejection fraction +1 point for every $10 \mathrm{ml} /$ min reduction in creatinine clearance below $60 \mathrm{ml} /$ $\mathrm{min} / 1.73 \mathrm{~m}^{2}$ (up to a maximum of 6 points)]), the Global Risk score (a combination of the SYNTAX score and EuroSCORE) and the EuroHeart score. ${ }^{18-27}$

The latest addition to this risk stratification mélange is the SYNTAX score II, which includes a nomogram for bedside application to obtain long-term mortality predictions for individual patients considering $\mathrm{CABG}$ or PCI. ${ }^{28}$ This score, which was externally validated in the multinational DELTA $(\mathrm{n}=2,891)$ and CredoKYOTO $(n=3,896)$ registries, ${ }^{8,29}$ consists of two anatomical (SYNTAX score and ULMCA disease) and six clinical (age, creatinine clearance, left ventricular ejection fraction, sex, chronic obstructive pulmonary disease and peripheral vascular disease) variables. Unlike the anatomical SYNTAX score, which is more predictive of clinical outcomes in patients undergoing PCI than in those undergoing $\mathrm{CABG}$, for whom it is not predictive, ${ }^{18,30}$ the SYNTAX score II provides individual mortality predictions for both $\mathrm{CABG}$ and PCI in addition to a measure of the magnitude of their differences, with clinically applicable accuracy. Currently, validation of the SYNTAX score II is a prespecified endpoint in the ongoing randomized EXCEL trial (NCT01205776) and the planned SYNTAX II trial, both of which will use SYNTAX score II to recruit patients on the grounds of patient safety. Early findings indicate the SYNTAX score II is equally predictive for long-term mortality between CABG and PCI in subjects with ULMCA disease up to an intermediate anatomical complexity. Both anatomical and clinical characteristics had a clear impact on long-term mortality predictions and decision-making between $\mathrm{CABG}$ and PCI. ${ }^{31}$

In this issue of Journal of Patient-Centered Research and Reviews, Nfor et al. ${ }^{32}$ report on the clinical outcomes after PCI with newer-generation DES (everolimus or zotarolimus in $\sim 80 \%$ patients) versus CABG in $3 \mathrm{VD} / \mathrm{ULMCA}$ on a nonrandomized "high risk" surgical cohort of select patients in their tertiary care institution. These patients were identified as "high risk" based on Society of Thoracic Surgeons 
(STS)-predicted operative mortality of $>5 \%$. Of note, approximately $40 \%$ of this cohort had an STS score $\geq 15$, qualifying them to be considered "extreme risk." Although, the mean STS score between the PCI and $\mathrm{CABG}$ groups did not significantly differ, more patients revascularized with PCI fell in the extreme risk category ( $63.9 \%$ vs. $28.9 \%, \mathrm{P}<0.001)$. Mean age of the population in the study was $77 \pm 9$ years with $42 \%$ of these being above the age of 80 years. In this high-risk surgical population there was no significant difference in the mean SYNTAX score between the PCI and $\mathrm{CABG}$ groups $(37.0 \pm 12$ vs. $40.0 \pm 15, \mathrm{P}=0.12)$. Given these characteristics of the population, it is quite evident the investigators were dealing with a subset of patients with advanced atherosclerotic cardiovascular disease demanding excellent clinical acumen and technical skills to achieve the best possible means of revascularization.

After a mean follow-up of approximately 3 years, the primary endpoint, a composite of death, myocardial infarction or stroke, occurred in $42.2 \%$ of PCI patients and $39.6 \%$ of CABG patients, an insignificant difference. The investigators also report no differences in the individual components of the primary endpoint between PCI and $\mathrm{CABG}$ as well as MACCE rates (50.6\% in PCI group vs. $42.2 \%$ in $\mathrm{CABG}$ group, $\mathrm{P}=0.23)$. However, the authors do report a threefold higher incidence of repeat revascularization in the PCI group compared with the $\mathrm{CABG}$ group.

The authors chose to retrospectively apply the STS risk model $^{33,34}$ to predict the risk of operative mortality and morbidity after adult cardiac surgery based on patient demographic and clinical variables. It is the most frequently used risk profile system in the United States and comprises more than 40 preoperative variables stratifying patients into low risk (STS score $\leq 3$ ), intermediate risk $(>3-8)$ and high risk $(>8)$. Although the STS score does not include variables like frailty, malnutrition, porcelain aorta and liver disease, and the cut-off STS scores may be arbitrary at best, it continues to be the best stratification process at present. The authors conclude that in patients with $3 \mathrm{VD} / \mathrm{ULMCA}$ and STS score $>5 \%$, PCI or CABG are similar with respect to long-term death, myocardial infarction or stroke, irrespective of individual SYNTAX scores.
These findings appear to contradict the landmark SYNTAX trial, the results and impact of which have already been detailed. These findings also are in contrast to a substudy of the SYNTAX trial ${ }^{18}$ that suggested patients with high clinical comorbidity, i.e. additive EuroSCORE $\geq 6$ with $3 \mathrm{VD}$ irrespective of the anatomical complexity (SYNTAX score) ${ }^{19}$ might derive a prognostic benefit from undergoing $\mathrm{CABG}$ rather than PCI provided an acceptable threshold of operative risk is not exceeded.

The combination of angiographic and clinical profiles allows clinicians to consider that PCI in subjects with ULMCA disease and a low-risk anatomical profile may be associated with a prognostic benefit, whereas more complex disease and a higher-risk clinical profile would remain the domain of $\mathrm{CABG}$ on the grounds of prognosis. Anatomical complexity of CAD can vary from a single lesion in the shaft of the left main coronary artery to distal trifurcation disease or involve left main disease with more complex downstream (three-vessel) disease. These variances may influence the capacity of PCI to achieve complete revascularization, the number of stents implanted and complexity of interventional techniques employed. Moreover, incomplete revascularization and anatomical complexity (residual SYNTAX score) have been directly correlated to late all-cause mortality following PCI. 11,35,36 This was demonstrated in the PCI arm of the ULMCA subgroup of SYNTAX, for which the incidence of 5-year all-cause mortality was shown to markedly increase in subjects with a SYNTAX score $\geq 33$ (5-year mortality of $20.9 \%$ ) compared with subjects with a SYNTAX score $<33$ (5-year mortality of $7.9 \%$ ). Conversely, in subjects undergoing CABG, anatomical complexity was shown to not affect longterm prognosis, as exemplified in the CABG arm of the ULMCA subgroup of SYNTAX, for which the incidence of 5-year all-cause mortality remained almost unchanged in subjects with a SYNTAX score $\geq 33$ (5year mortality of $14.1 \%$ ) compared with subjects with a SYNTAX score $<33$ (5-year mortality of $15.1 \%$ ). ${ }^{11}$

\section{SYNTAX in the Contemporary Era}

It is important to note that improved clinical outcomes with the everolimus-eluting stent - the most used stent in Nfor et al.'s study $\left(\sim 59 \% 0^{32}\right)$ - in multivessel disease,${ }^{37}$ coupled with similarly reported data from the 
French Left Main Taxus and LEMAX registries that investigated left main stenting with everolimus-eluting stents $^{38,39}$ and the known reductions in stent thrombosis of newer-generation DES, ${ }^{40-47}$ implies that if newergeneration DES had been used in the SYNTAX trial, there would have been a significant reduction in repeat revascularization and myocardial infarction. It is also plausible that reductions in mortality would have been seen with the newer-generation DES ${ }^{47}$ Thus, because the SYNTAX trial used the first-generation paclitaxeleluting stent exclusively, it is not inconceivable that contemporary PCI using everolimus stents may outperform results of paclitaxel since randomized comparisons of everolimus- versus paclitaxel-eluting stents have consistently shown everolimus to be associated with more favorable outcomes. ${ }^{45,48-50} \mathrm{In}$ addition, the largest patient population meta-analysis $(\mathrm{N}=4,989)$ of the SPIRIT clinical program showed that everolimus-eluting stents were superior to paclitaxeleluting stents in reducing all-cause mortality $(3.2 \%$ vs. $5.1 \%$, hazard ratio: $0.65,95 \%$ confidence interval: 0.49-0.86, $\mathrm{P}=0.003) .{ }^{51}$ However, in the SYNTAX trial, if the cardiac mortality events related to stent thrombosis (as defined by Academic Research Consortium $^{52}$ ) were removed, there would have been only a modest reduction in cardiac mortality at 5 years: $9 \%$ to $8.5 \%$ for definite stent thrombosis, and $9 \%$ to $7.5 \%$ for definite or probable stent thrombosis. ${ }^{53}$ The main hypothesis behind this is that bypass grafts protect coronary vessels from future myocardial infarctions for the lifespan of the graft, particularly in more complex CAD for which the plaque burden and risk of future myocardial infarction is potentially higher than in less complex CAD. Conversely, stents would only treat individual lesions. ${ }^{18,54}$

Thus, the potential reduction in mortality with newergeneration DES in the SYNTAX trial would be unlikely to bridge the gap between CABG and PCI, particularly with more complex CAD. ${ }^{55}$ This is exemplified in the SYNTAX score II, which identifies subsets of patients across all tertiles of the SYNTAX score who would have a mortality benefit from undergoing one type of revascularization over the other. It should be emphasized that increased anatomical complexity, particularly in subjects with $3 \mathrm{VD}$, led to a greater mortality benefit with $\mathrm{CABG}$ as opposed to PCI. ${ }^{55}$ Investigators in the EXCEL trial recruited 1,905 patients with left main disease and mild-to-moderate anatomical complexity (SYNTAX score $\leq 32$ ) and randomly assigned them to undergo either PCI with second-generation DES or CABG surgery. This study could be pivotal in providing support for the efficacy and safety of PCI in this lesion type.

With consistent improvement in PCI outcomes, a wider spectrum of patients with complex CAD is being treated in this fashion. Currently, both European and North American guidelines recommend PCI as a valuable treatment option for patients with ULMCA disease and as an alternative to $\mathrm{CABG}$ in patients with less complex 3 VD (SYNTAX score $<23$ ). ${ }^{56,57}$ For prudent decision-making, it is essential to consider the risk/benefit ratio of PCI and CABG for $3 \mathrm{VD}$, weighing procedural invasiveness and associated short-term complications against the long-term event rates of death, myocardial infarction, repeat revascularization and health-related quality of life.

\section{Striking a Balance}

The clinician must never underestimate the role of the individual patient and his or her personal preferences or perception of risk related to $\mathrm{CABG}$ and PCI. Individual patients may value the risk/benefit trade-off between CABG and PCI differently. Remaining active in their professional/personal lives may be vital for some. Those people would thus be more prepared to accept the longer-term risks of PCI (in particular an increased risk of repeat revascularization) compared to the short-term morbidity effects associated with the more invasive nature of CABG in order to obtain short-term pain relief and a rapid return to full mobility. ${ }^{58,59}$ Others may prefer to endure short-term pain to obtain a higher probability of avoiding a subsequent revascularization. Some patients may prefer to risk undergoing multiple PCI procedures compared with a single $\mathrm{CABG}$, or they may prefer to undergo $C A B G$ initially to avoid the risk of requiring $\mathrm{CABG}$ subsequent to PCI. Consequently, from the patient's perspective, the balance between these conflicting considerations plays a crucial role in selecting the preferred revascularization strategy. Applying this concept to quantify the trade-off between the risks and benefits of PCI versus CABG (such as freedom from chest pain and improvement in healthrelated quality-of-life measures) for patients with multivessel disease, it was recently shown for the first 


\section{HEART TEAM APPROACH}

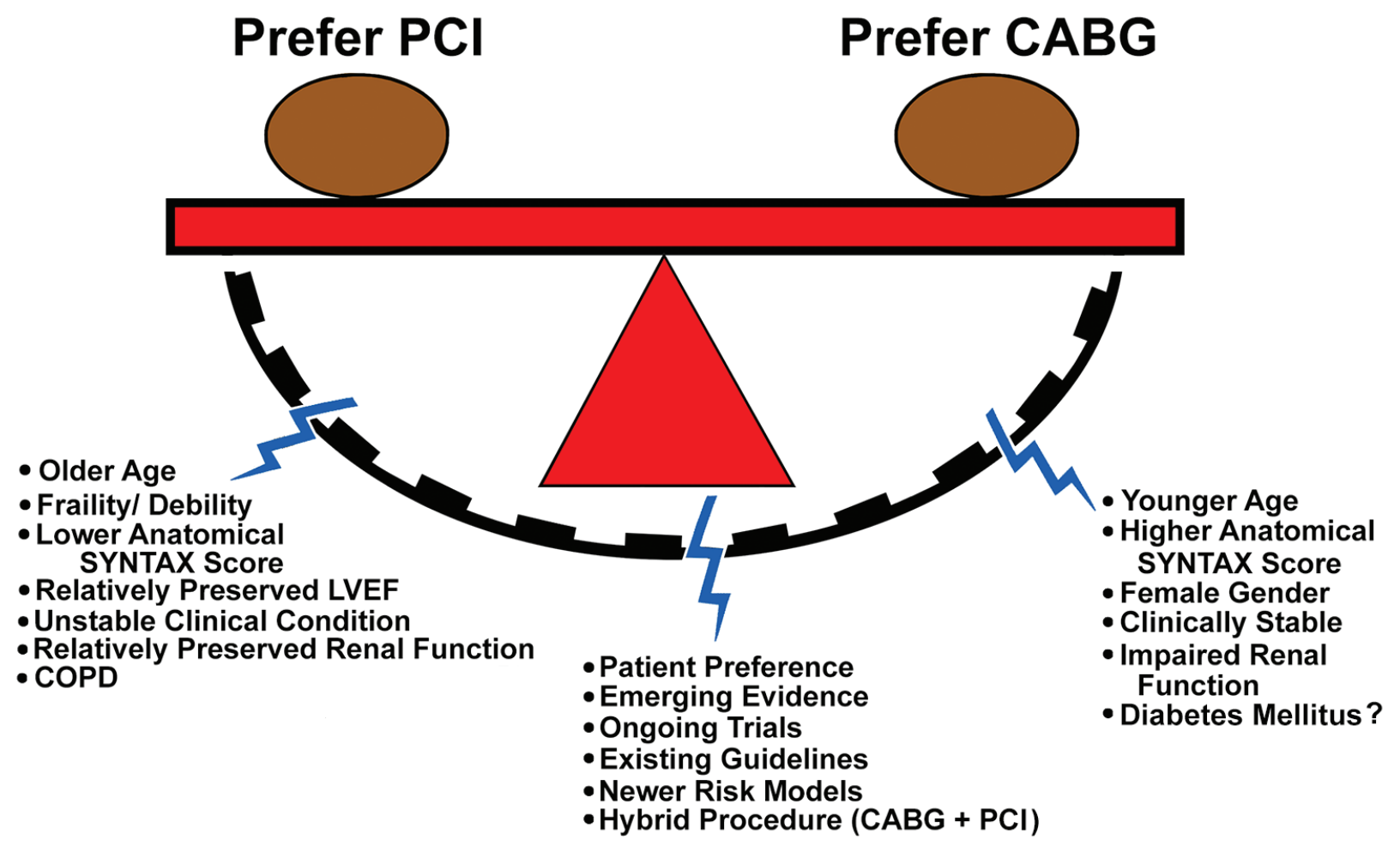

Figure 1. The balancing act between $C A B G$ and $P C I$. The fundamental principal behind revascularization of coronary artery disease in patients with multivessel disease and/or unprotected left main disease should not be viewed as a principal of war between the two strategies (as in A Tale of Two Cities). Revascularization should be viewed as a continuum of the evolution of the best possible strategy wherein patient preferences are taken into account. International guidelines, particularly those from the American College of Cardiology, American Heart Association and European Society of Cardiology, aim to be balanced, practical, patient-oriented and evidence-based, and should form the general framework of local, regional and national protocols for revascularization. Practice should regularly be audited to ensure best practices. There are clearly trade-offs between the two revascularization strategies that need to be discussed with patients as part of the shared decision-making process. The early hazard of CABG (risk of stroke) may be unacceptable to some patients, whereas others might want to avoid the later hazards of $\mathrm{PCl}$ (risk of needing a repeat $\mathrm{PCl}$ or having a myocardial infarction). The decision also should take into account whether complete revascularization with $\mathrm{PCl}$ appears to be feasible (i.e. residual SYNTAX score).

time that it is possible to quantify a level of risk that a patient would be able to accept in order to maintain present functional state. ${ }^{60}$

To achieve a reasonable balance in the clinical approach to revascularization of multivessel disease, key factors in decision-making will require a Heart Team to weigh patient wishes, approved guidelines, local expertise and skills, available resources, and regional medical, legal and ethical considerations (Figure 1). Therefore, risk stratification (SYNTAX, SYNTAX II, STS, euroSCORE, etc.) should be used only as a guide; clinical judgment and review by a Heart Team remain indispensable. Finally, surgeons and interventional cardiologists should remember that ongoing optimal medical therapy and risk-factor management is essential for the best long-term prognosis after $\mathrm{CABG}$ surgery or PCI. 
Whether the preferred revascularization modality will change with advances in technology is the subject of ongoing and future trials. In both the EXCEL trial and the SYNTAX II trial, the SYNTAX score and SYNTAX score II, respectively, are being used to recruit subjects on the grounds of patient safety. Further study will continue to delineate the boundaries between CABG and PCI to best define the optimal revascularization modality for individual patients with complex CAD. Irrespective of the results of these trials, it should be emphasized that treatment recommendations for patients with complex CAD need to be undertaken in the context of the multidisciplinary Heart Team, in open dialogue with the patient, rather than by an individual practitioner. This is because individual patient perceptions of short- and long-term risk are important factors in decision-making. The goal should be to fit the patient with the best technique, not to force the patient into the technique. To paraphrase Hippocrates: It is more important to know what sort of person has a high SYNTAX or STS score than to know what sort of SYNTAX or STS score a person has.

\section{Conflicts of Interest}

None.

\section{REFERENCES}

1. Favaloro RG, Effler DB, Groves LK, Fergusson DJ, Lozada JS. Double internal mammary artery-myocardial implantation. Clinical evaluation of results in 150 patients. Circulation. 1968;37:549-55. CrossRef

2. Grüntzig AR, Senning A, Siegenthaler WE. Nonoperative dilatation of coronary-artery stenosis: percutaneous transluminal coronary angioplasty. NEngl JMed. 1979;301:618. CrossRef

3. Sipahi I, Akay MH, Dagdelen S, Blitz A, Alhan C. Coronary artery bypass grafting vs percutaneous coronary intervention and long-term mortality and morbidity in multivessel disease: meta-analysis of randomized clinical trials of the arterial grafting and stenting era. JAMA Intern Med. 2014;174:22330. $\underline{\text { CrossRef }}$

4. Weintraub WS, Grau-Sepulveda MV, Weiss JM, et al. Comparative effectiveness of revascularization strategies. $N$ Engl J Med. 2012;366:1467-76. CrossRef

5. Bangalore S, Guo Y, Samadashvili Z, Blecker S, Xu J, Hannan EL. Everolimus-eluting stents or bypass surgery for multivessel coronary disease. $N$ Engl J Med. 2015;372:121322. $\underline{\text { CrossRef }}$

6. Park SJ, Ahn JM, Kim YH, et al. Trial of everolimus-eluting stents or bypass surgery for coronary disease. $N$ Engl $J$ Med. 2015;372:1204-12. CrossRef

7. Soran O, Manchanda A, Schueler S. Percutaneous coronary intervention versus coronary artery bypass surgery in multivessel disease: a current perspective. Interact Cardiovasc Thorac Surg. 2009;8:666-71. CrossRef

8. Serruys PW, Morice MC, Kappetein AP, et al. Percutaneous coronary intervention versus coronary-artery bypass grafting for severe coronary artery disease. $N$ Engl $J$ Med. 2009;360:961-72. CrossRef

9. Ong AT, Serruys PW, Mohr FW, et al. The SYNergy between percutaneous coronary intervention with TAXus and cardiac surgery (SYNTAX) study: design, rationale, and run-in phase. Am Heart J. 2006;151:1194-204. CrossRef

10. Mohr FW, Morice MC, Kappetein AP, et al. Coronary artery bypass graft surgery versus percutaneous coronary intervention in patients with three-vessel disease and left main coronary disease: 5-year follow-up of the randomised, clinical SYNTAX trial. Lancet. 2013;381:629-38. CrossRef

11. Morice MC, Serruys PW, Kappetein AP, et al. Five-year outcomes in patients with left main disease treated with either percutaneous coronary intervention or coronary artery bypass grafting in the synergy between percutaneous coronary intervention with taxus and cardiac surgery trial. Circulation. 2014;129:2388-94. CrossRef

12. Sianos G, Morel MA, Kappetein AP, et al. The SYNTAX Score: an angiographic tool grading the complexity of coronary artery disease. EuroIntervention. 2005;1:219-27.

13. Farooq V, Brugaletta S, Serruys PW. Contemporary and evolving risk scoring algorithms for percutaneous coronary intervention. Heart. 2011;97:1902-13. CrossRef

14. Leaman DM, Brower RW, Meester GT, Serruys P, van den Brand M. Coronary artery atherosclerosis: severity of the disease, severity of angina pectoris and compromised left ventricular function. Circulation. 1981;63:285-99. CrossRef

15. Medina A, Suárez de Lezo J, Pan M. [A new classification of coronary bifurcation lesions]. Rev Esp Cardiol. 2006;59:183. CrossRef

16. Hamburger JN, Serruys PW, Scabra-Gomes R, et al. Recanalization of total coronary occlusions using a laser guidewire (the European TOTAL Surveillance Study). Am J Cardiol. 1997;80:1419-23. CrossRef

17. Applegate RJ. Toward better stratification of patients with left main disease: value of clinical and angiographic-derived risk scores. JACC Cardiovasc Interv. 2011;4:298-9. CrossRef

18. Serruys PW. Farooq V, Vranckx P, et al. A global risk approach to identify patients with left main or 3-vessel disease who could safely and efficaciously be treated with percutaneous coronary intervention: the SYNTAX Trial at 3 years. JACC Cardiovasc Interv. 2012;6: 606-17. CrossRef

19. Roques F, Michel P, Goldstone AR, Nashef SA. The logistic EuroSCORE. Eur Heart J. 2003;24:881-2. CrossRef

20. Nashef SA, Roques F, Michel P, Gauducheau E, Lemeshow S, Salamon R. European system for cardiac operative risk evaluation (EuroSCORE). Eur $J$ Cardiothorac Surg. 1999;16:9-13. CrossRef

21. Ranucci M, Castelvecchio S, Menicanti L, Frigiola A, Pelissero G. Risk of assessing mortality risk in elective cardiac operations: age, creatinine, ejection fraction, and the law of parsimony. Circulation. 2009;119:3053-61. CrossRef

22. Ranucci M, Castelvecchio S; Surgical and Clinical Outcome Research (SCORE) group. The ACEF score one year after: a skeleton waiting for muscles, skin, and internal organs. EuroIntervention. 2010;6:549-53. CrossRef

23. Capodanno D, Miano M, Cincotta G, et al. EuroSCORE 
refines the predictive ability of SYNTAX score in patients undergoing left main percutaneous coronary intervention. $\mathrm{Am}$ Heart J. 2010;159:103-9. CrossRef

24. Capodanno D, Caggegi A, Miano M, et al. Global risk classification and clinical SYNTAX (synergy between percutaneous coronary intervention with TAXUS and cardiac surgery) score in patients undergoing percutaneous or surgical left main revascularization. JACC Cardiovasc Interv. 2011;4:287-97. CrossRef

25. de Mulder M, Gitt A, van Domburg R, et al. EuroHeart score for the evaluation of in-hospital mortality in patients undergoing percutaneous coronary intervention. Eur Heart J. 2011;32:1398-408. CrossRef

26. Farooq V, Vergouwe Y, Räber L, et al. Combined anatomical and clinical factors for the long-term risk stratification of patients undergoing percutaneous coronary intervention: the Logistic Clinical SYNTAX score. Eur Heart J. 2012;33:3098104. $\underline{\text { CrossRef }}$

27. Farooq V, Vergouwe Y, Généreux P, et al. Prediction of 1 -year mortality in patients with acute coronary syndromes undergoing percutaneous coronary intervention: validation of the logistic clinical SYNTAX (Synergy Between Percutaneous Coronary Interventions With Taxus and Cardiac Surgery) score. JACC Cardiovasc Interv. 2013;6:737-45. CrossRef

28. Farooq V, van Klaveren D, Steyerberg EW, et al. Anatomical and clinical characteristics to guide decision making between coronary artery bypass surgery and percutaneous coronary intervention for individual patients: development and validation of SYNTAX score II. Lancet. 2013;381:639-50. CrossRef

29. Campos CM, van Klaveren D, Iqbal J, et al. Predictive performance of SYNTAX Score II in patients with left main and multivessel coronary artery disease - analysis of CREDO-Kyoto registry. Circ J. 2014;78:1942-9. CrossRef

30. Serruys PW, Onuma Y, Garg S, et al. Assessment of the SYNTAX score in the Syntax study. EuroIntervention. 2009;5:50-6. CrossRef

31. Campos CM, van Klaveren D, Farooq V, et al. Long-term forecasting and comparison of mortality in the Evaluation of the Xience Everolimus Eluting Stent vs. Coronary Artery Bypass Surgery for Effectiveness of Left Main Revascularization (EXCEL) trial: prospective validation of the SYNTAX Score II. Eur Heart J. 2015;36:1231-41. CrossRef

32. Nfor T, Shetabi K, Hassan W, et al. Clinical outcomes after drug-eluting stents versus coronary artery bypass surgery in high surgical risk patients with left main or three-vessel coronary artery disease. $J$ Patient-Centered Res Rev. 2015;2:95-103.

33. Anderson RP. First publications from the Society of Thoracic Surgeons National Database. Ann Thorac Surg. 1994;57:6-7. CrossRef

34. Shahian DM, O'Brien SM, Filardo G, et al. The Society of Thoracic Surgeons 2008 cardiac surgery risk models: part 1 - coronary artery bypass grafting surgery. Ann Thorac Surg. 2009;88:S2-22. CrossRef

35. Farooq V, Serruys PW, Bourantas CV, et al. Quantification of incomplete revascularization and its association with fiveyear mortality in the synergy between percutaneous coronary intervention with taxus and cardiac surgery (SYNTAX) trial validation of the residual SYNTAX score. Circulation. 2013;128:141-51. CrossRef
36. Généreux P, Campos CM, Yadav M, et al. Reasonable incomplete revascularisation after percutaneous coronary intervention: the SYNTAX Revascularisation Index. EuroIntervention. 2014 Oct 14 [Epub ahead of print].

37. Ribichini F, Romano M, Rosiello R, et al. A clinical and angiographic study of the XIENCE V everolimus-eluting coronary stent system in the treatment of patients with multivessel coronary artery disease: the EXECUTIVE trial (EXecutive RCT: evaluating XIENCE V in a multi vessel disease). JACC Cardiovasc Interv. 2013;6:1012-22. CrossRef

38. Moynagh A, Salvatella N, Harb T, et al. Two-year outcomes of everolimus vs. paclitaxel-eluting stent for the treatment of unprotected left main lesions: a propensity score matching comparison of patients included in the French Left Main Taxus (FLM Taxus) and the LEft MAin Xience (LEMAX) registries. EuroIntervention. 2013;9:452-62. CrossRef

39. Farooq V, Serruys PW, Stone GW, Virmani R, Chieffo A, Fajadet J. Left main coronary artery disease. In: Eeckhout E, Serruys PW, Wijns W, Vahanian A, van Sambeek M, De Palma R (eds). Percutaneous Interventional Cardiovascular Medicine. The PCR-EAPCI Textbook, Volume 2, Part III. Toulouse, France: PCR Publishing and Europa Edition, 2012, pp. 407-45.

40. Palmerini T, Biondi-Zoccai G, Della Riva D, et al. Stent thrombosis with drug-eluting and bare-metal stents: evidence from a comprehensive network meta-analysis. Lancet. 2012;379:1393-402. $\underline{\text { CrossRef }}$

41. Bangalore S, Kumar S, Fusaro M, et al. Short- and long-term outcomes with drug-eluting and bare-metal coronary stents: a mixed-treatment comparison analysis of 117762 patientyears of follow-up from randomized trials. Circulation. 2012;125:2873-91. CrossRef

42. Meredith IT, Verheye S, Dubois CL, et al. Primary endpoint results of the EVOLVE trial: a randomized evaluation of a novel bioabsorbable polymer-coated, everolimus-eluting coronary stent. J Am Coll Cardiol. 2012;59:1362-70. CrossRef

43. Serruys PW, Farooq V, Kalesan B, et al. Improved safety and reduction in stent thrombosis associated with biodegradable polymer-based biolimus-eluting stents versus durable polymerbased sirolimus-eluting stents in patients with coronary artery disease: final 5-year report of the LEADERS (Limus Eluted From A Durable Versus ERodable Stent Coating) randomized, noninferiority trial. JACC Cardiovasc Interv. 2013;6:777-89. CrossRef

44. Planer D, Smits PC, Kereiakes DJ, et al. Comparison of everolimus- and paclitaxel-eluting stents in patients with acute and stable coronary syndromes: pooled results from the SPIRIT (A Clinical Evaluation of the XIENCE V Everolimus Eluting Coronary Stent System) and COMPARE (A Trial of Everolimus-Eluting Stents and Paclitaxel-Eluting Stents for Coronary Revascularization in Daily Practice) Trials. JACC Cardiovasc Interv. 2011;4:1104-15. CrossRef

45. Kedhi E, Joesoef KS, McFadden E, et al. Second-generation everolimus-eluting and paclitaxel-eluting stents in reallife practice (COMPARE): a randomised trial. Lancet. 2010;375:201-9. CrossRef

46. Serruys PW, Silber S, Garg S, et al. Comparison of zotarolimuseluting and everolimus-eluting coronary stents. $N$ Engl J Med. 2010;363:136-46. CrossRef

47. Sarno G, Lagerqvist B, Fröbert O, et al. Lower risk of stent thrombosis and restenosis with unrestricted use of 'new- 
generation' drug-eluting stents: a report from the nationwide Swedish Coronary Angiography and Angioplasty Registry (SCAAR). Eur Heart J. 2012;33:606-13. CrossRef

48. Gada H, Kirtane AJ, Newman W, et al. 5-year results of a randomized comparison of XIENCE $\mathrm{V}$ everolimus-eluting and TAXUS paclitaxel-eluting stents: final results from the SPIRIT III trial (clinical evaluation of the XIENCE V everolimus eluting coronary stent system in the treatment of patients with de novo native coronary artery lesions). JACC Cardiovasc Interv. 2013;6:1263-6. CrossRef

49. Brener SJ, Kereiakes DJ, Simonton CA, et al. Everolimuseluting stents in patients undergoing percutaneous coronary intervention: final 3-year results of the Clinical Evaluation of the XIENCE V Everolimus Eluting Coronary Stent System in the Treatment of Subjects With de Novo Native Coronary Artery Lesions trial. Am Heart J. 2013;166:1035-42. CrossRef

50. Stone GW, Rizvi A, Newman W, et al. Everolimus-eluting versus paclitaxel-eluting stents in coronary artery disease. $N$ Engl J Med. 2010;362:1663-74. CrossRef

51. Dangas GD, Serruys PW, Kereiakes DJ, et al. Meta-analysis of everolimus-eluting versus paclitaxel-eluting stents in coronary artery disease: final 3-year results of the SPIRIT clinical trials program (Clinical Evaluation of the Xience V Everolimus Eluting Coronary Stent System in the Treatment of Patients With De Novo Native Coronary Artery Lesions). JACC Cardiovasc Interv. 2013;6:914-22. CrossRef

52. Cutlip DE, Windecker S, Mehran R, et al. Clinical end points in coronary stent trials: a case for standardized definitions. Circulation. 2007;115:2344-51. CrossRef

53. Farooq V, Serruys PW, Zhang Y, et al. Short-term and longterm clinical impact of stent thrombosis and graft occlusion in the SYNTAX trial at 5 years: Synergy Between Percutaneous Coronary Intervention with Taxus and Cardiac Surgery trial. $J$ Am Coll Cardiol. 2013;62:2360-9. CrossRef

54. Taggart DP. Thomas B. Ferguson Lecture. Coronary artery bypass grafting is still the best treatment for multivessel and left main disease, but patients need to know. Ann Thorac Surg. 2006;82:1966-75. CrossRef

55. Farooq V, Serruys PW. Complex coronary artery disease: would outcomes from the SYNTAX (synergy between percutaneous coronary intervention with taxus and cardiac surgery) trial have differed with newer-generation drug-eluting stents? JACC Cardiovasc Interv. 2013;6:1023-5. CrossRef

56. Task Force on Myocardial Revascularization of the European Society of Cardiology (ESC) and the European Association for Cardio-Thoracic Surgery (EACTS); European Association for Percutaneous Cardiovascular Interventions (EAPCI), Wijns W, et al. Guidelines on myocardial revascularization. Eur Heart J. 2010;31:2501-55. CrossRef

57. Levine GN, Bates ER, Blankenship JC, et al. 2011 ACCF/AHA/SCAI Guideline for Percutaneous Coronary Intervention: executive summary: a report of the American College of Cardiology Foundation/American Heart Association Task Force on Practice Guidelines and the Society for Cardiovascular Angiography and Interventions. Circulation. 2011;124:2574-609. CrossRef

58. van Domburg RT, Daemen J, Morice MC, et al. Short- and long-term health related quality-of-life and anginal status of the Arterial Revascularisation Therapies Study part II, ARTS-II; sirolimus-eluting stents for the treatment of patients with multivessel coronary artery disease. EuroIntervention. 2010;5:962-7. CrossRef

59. Cohen DJ, Van Hout B, Serruys PW, et al. Quality of life after PCI with drug-eluting stents or coronary-artery bypass surgery. N Engl J Med. 2011;364:1016-26. CrossRef

60. Federspiel JJ, Stearns SC, van Domburg R, Sheridan BC, Lund JL, Serruys PW. Risk-benefit trade-offs in revascularisation choices. EuroIntervention. 2011;6:936-41. CrossRef

(C) 2015 Aurora Health Care, Inc. 